\title{
Ameliorative Effects of Soya Bean Oil and Vitamin C on Liver Enzymes in Ethanol -Induced Oxidative Stress in Wistar Rats
}

\author{
${ }^{1}$ Mallo, M.J., ${ }^{1}$ Tanko, Y and ${ }^{2}$ Mabrouk, M.A. \\ ${ }^{1}$ Department of Human Physiology, Ahmadu Bello University, Zaria, Nigeria. \\ .$^{2}$ Department of Human Physiology, Bayero University, Kano, Nigeria.
}

\begin{abstract}
The protective potential of soya bean oil and vitamin $C$ on Ethanol-induced oxidative stress in Wistar rats was evaluated. Thirty five Wistar rats of both sexes weighing 120-200g were grouped into five groups of seven rats each. Oxidative stress was induced by administration of $20 \%$ ethanol $(w / v)$ for 28 days, at the end of the period of administration, the rats were fasted over night and their blood was collected directly from the heart via cardiac puncture in EDTA sample bottles and the blood was centrifuged and the serum was used to determine the levels of of AST, ALT and ALP in all the groups. The result revealed that Ethanol significantly $(p<0.05)$ increased plasma AST, ALT and ALP levels. Vitamin C significantly $(p<0.05)$ decreased serum AST while soya bean oil produced no significant $(p<0.05)$ effect on plasma AST. The serum levels of ALT and ALP were significantly reduced following vitamin $C$ and Soya bean oil administration. The elevation of serum AST, $A L T$ and ALP after alcohol administration is an indication oxidative stress. The decrease in plasma concentration of the liver enzymes after treatment with vitamin $C$ and Soya bean oil reveals the ameliorative potential of vitamin $C$ and soya bean oil against ethanol-induced oxidative stress in Wistar rats.
\end{abstract}

Key words: Ethanol, Oxidative stress, Liver enzymes Vitamin C, Soya bean

\section{Introduction}

The liver is the largest internal organ in the body, constituting about $2.5 \%$ of an adult's body weight, approximately $1500 \mathrm{~g}[1]$. In the late fetus, in which it also serves as hematopoietic organ it is proportionately twice as large (5\% of the body weight) [2 ] . During rest, it receives $25 \%$ of the cardiac output via the hepatic portal vein and hepatic artery. The hepatic portal vein carries the absorbed nutrients from the GI tract to the liver, which takes up, stores, and distributes nutrients and vitamins [1 ]. Liver enzymes are proteins that help speed up a chemical reaction within the liver. They perform a variety of functions in the body such as filtration and cleansing of the blood, excretion and metabolism. The liver is greatly involved in removing toxins from the body. Liver enzymes are normally present in liver cells, and in case of injury to liver cells, they are spilled into the blood stream. Documenting a raised level of these enzymes in blood serves as an initial marker of liver disease. Among the commonly used liver enzymes are aminotransferases. They include aspartate aminotransferase (AST or SGOT) and alanine aminotransferases (ALT or SGPT). Another group of liver enzymes are cholestatic liver enzymes; alkaline phosphatase (AP) and gamma glutamyl transferase (GGT). When do aminotransferase levels increase? Processes that cause extensive death of liver cells lead to an increase in aminotransferases. Alcohol is a chemical compound and is the active ingredient in beer, wine, whisky, gin, brandy and so on. Alcohol appears in the blood within five minutes of its being drunk and disappears in an hour or two hours later [3]. It is the most widely used drug in the western society, and it is also one of the most popular drinks in Nigeria. More men than female are known to be engaged in alcohol consumption, cigarette smoking and abuse of psychotropics [4]. There is always high alcohol consumption in Nigeria particularly during festive periods for instance, birthdays, wedding toasts, professional graduation ceremonies such as tailoring, trading and so on. The relationship between alcohol consumption and health outcome is complex and multidimensional [5]. Excessive alcohol usage is the third leading cause of preventable death in United States [6]. Alcohol usage leads to dependence, which is a serious medical illness, experienced by about $14 \%$ of alcohol users [7, 8]. Alcohol dependence causes about $\$ 184$ billion in expenditures arising from alcohol related chronic diseases such as heart diseases [9], Alzheimer's disease [10], stroke [11], liver disease [12], cancer [13], chronic respiratory disease [14], diabetes mellitus [15], and bone disease [16], which may develop following chronic alcohol ingestion and contribute to the alcoholism related high morbidity and mortality. The relationship between alcohol consumption and liver disease was recognized more than 200 years ago [17]. The liver is particularly susceptible to alcohol-related injury because it is the primary site of alcohol metabolism. Some products generated from alcohol metabolism are even more toxic than the alcohol itself e.g., acetaldehyde, free radicals are also generated during alcohol metabolism which also damages the liver cells and promotes impairment of vital functions such as energy generation. The antioxidants which are the body's defense system are against free radicals are also inhibited by alcohol leading to increased liver damage [18]. Symptoms of liver damage may not appear immediately until the damage is quite extensive due to its considerable reserve. 
Epidemiological studies revealed that a threshold dose of alcohol must be consumed for serious liver injury to become apparent [19]. Soybean meal is the material remaining after solvent extraction of oil from soybean flakes, with a 50\% soy protein content. The meal is 'toasted' (a misnomer because the heat treatment is with moist steam) and ground in a hammer mill. Soybean meal is an essential element of the American production method of growing farm animals, such as poultry and swine, on an industrial scale that began in the 1930s; and more recently the aquaculture of catfish. Ninety-eight percent of the U.S. soybean crop is used for livestock feed [20].

\subsection{Location of Study}

\section{Materials and Methods}

The research was conducted in the Department of Human Physiology Faculty of Medicine, Ahmadu Bello University, Zaria. Nigeria and Department of Chemical Pathology, Ahmadu Bello University, Teaching Hospital Shika, Zaria, Nigeria.

\subsection{Drugs}

All chemical and drugs were obtained commercially and were of analytical grade. Soya bean oil was purchased from Grand Cereal and oil mills Limited Jos, Nigeria.

\subsection{Animals Management}

Thirty five (35) Wistar rats of both sexes were used for this research; the animals were purchased from the animal house, Federal College of Animal Health, National Veterinary Research Institute, Vom, Plateau State, Nigeria. The rats were housed in the animal house of the Department of Human Physiology Faculty of Medicine, Ahmadu Bello University Zaria, Nigeria. The animals were kept in cages under normal environmental temperature and were fed with standard pellet diet and water given ad libitum. The rats were allowed to acclimatize to the laboratory environment for one week before the experiment commenced. This research was carried out in Ahmadu Bello University in accordance with the rules governing the use of laboratory animals as accepted internationally.

\subsection{Induction of Oxidative Stress}

This research was conducted as described by[21] as modified by )[22] in which oxidative liver damage was induced by oral administration of ethanol $(20 \% \mathrm{w} / \mathrm{v})$ at a dose of $5 \mathrm{ml} / \mathrm{kg}$, the treatment lasted for a period of four weeks.

\subsection{Experimental design}

After the induction of oxidative stress in the Wistar rats, the animals were randomly divided into experimental and control groups. All the animals were sacrificed at the end of the four weeks. The rats were anaesthetized at the time of sacrifice by being placed in sealed cotton wool soaked chloroform inhalation jar. Blood was collected via cardiac puncture from each animal for determination of the parameters. The Wistar rats were subdivided as follows;

Group $1(\mathrm{n}=7)$ : control Normal Wistar rats( Received Distilled water)

Group 2 (n=7): Received 20\% w/v Ethanol only.

Group 3 ( $\mathrm{n}=7$ ): Received $20 \% \mathrm{w} / \mathrm{v}$ Ethanol and $10 \mathrm{mg} / \mathrm{kg}$ of Vitamin C

Group $4(\mathrm{n}=7)$ : Received $20 \% \mathrm{w} / \mathrm{v}$ Ethanol and $5 \mathrm{mg} / \mathrm{kg}$ of Soya Bean Oil

Group 5(n=7): Received 20\% w/v Ethanol, 10mg/kg Vitamin C and $5 \mathrm{mg} / \mathrm{kg}$ of Soya Bean Oil

\subsection{Determination of liver enzymes}

Adopting the method of [23], the levels of alkaline phosphatase, alanine and aspartate aminotransferases were determined in the serum using assay kits from Randox using Automated Bayer chemistry analyzer Express plus system 2004 ( Bayer Healthcare,LLC,9664,Fast 4 system Tarrytown,NY,10591-5097,USA).

\subsection{Data Analysis}

All the data are expressed as mean \pm SEM. Statistical comparisons were performed by one way analysis of variance (ANOVA) followed by Duncan's multiple range tests [ 24]. The results were considered statistically significant if the $\mathrm{p}$ values were 0.05 or less. 


\section{Results}

Table 1 Effect of Soya Bean oil and Vitamin C on Liver enzymes in alcohol-induced Oxidative Stress in Wistar rats

\begin{tabular}{|c|c|c|c|c|c|}
\hline \multirow[t]{2}{*}{ Groups } & \multirow{2}{*}{$\begin{array}{c}\text { AST } \\
\text { ( I.U/L) }\end{array}$} & \multicolumn{3}{|c|}{ ALP } & \multirow[t]{2}{*}{ ALT } \\
\hline & & ( I.U/L) & & ( I.U/L) & \\
\hline $\begin{array}{l}\text { Normal control (NS) } \\
1.65\end{array}$ & $13.00 \pm 1.47$ & 60.50 & \pm 2.50 & & $22.25 \pm$ \\
\hline Ethanol Induced & $19.75 \pm 1.49$ & $73.75 \pm 8.08$ & & 47.75 & \pm 2.32 \\
\hline $\begin{array}{l}\text { Ethanol + vitamin C } \\
2.65^{\mathrm{a}}\end{array}$ & $15.75 \pm 1.03^{\mathrm{a}}$ & 69.50 & $\pm 1.94^{\mathrm{a}}$ & & $35.00 \pm$ \\
\hline $\begin{array}{l}\text { Ethanol + Soya oil } \\
2.18^{\mathrm{a}}\end{array}$ & $17.75 \pm 1.44$ & 67.00 & $\pm 1.29^{\mathrm{a}}$ & & $39.75 \pm$ \\
\hline Ethanol + Vitamin C + Soya oil & $18.75 \pm 0.75$ & $61.50 \pm 2.75^{\mathrm{a}}$ & 33.00 & $\pm 2.48^{\mathrm{a}}$ & \\
\hline
\end{tabular}

$\mathrm{a}=$ significance $(\mathrm{p}<0.05)$ when compared to ethanol group

\section{Discussion}

Alcohol significantly $(\mathrm{p}<0.05)$ increased AST level $(19.75 \pm 1.49)$ as compared to the normal control group $(13.00 \pm 1.47)$ while vitamin C significantly $(\mathrm{p}<0.05)$ decreased AST level $(15.75 \pm 1.03)$ as compared to the ethanol treated group $(19.75 \pm 1.49)$. However, soya bean oil showed no significant effect on serum AST $(17.75 \pm 1.44)$ when compared to the ethanol treated group $(19.75 \pm 1.49)$. Also, the group treated with vitamin $\mathrm{C}$ combined with soya bean oil showed no significant $(\mathrm{p}<0.05)$ effect when compared to the ethanol-induced group. The result of serum ALT showed that ethanol significantly $(\mathrm{p}<0.05)$ increased the serum concentration of ALT $(47.75 \pm 2.32)$ as compared to the normal control group $(22.25 \pm 1.65)$, however, vitamin C significantly $(\mathrm{p}<0.05)$ decreased ALT $(35.00 \pm 2.65)$ as compared to the ethanol group $(47.75 \pm 2.32)$, the group treated with soya bean oil revealed a significant $(\mathrm{p}<0.05)$ decreased in ALT $(39.75 \pm 2.18)$ as compared to the ethanol group $(47.75 \pm 2.32)$. Also, the group that received vitamin $C$ combined with soya bean oil showed a significant $(\mathrm{p}<0.05)$ decreased in ALT $(33.00 \pm 2.48)$ as compared to the ethanol group $(47.75 \pm 2.32)$. The result also revealed that ethanol significantly $(\mathrm{p}<0.05)$ increased ALP $(73.75 \pm 8.08)$ when compared to the normal control group $(60.50 \pm 2.50)$, but treatment with vitamin $\mathrm{C}$ produced significant $(\mathrm{p}<0.05)$ decreased in ALP $(69.50 \pm$ $1.94)$ as compared to the ethanol group $(73.75 \pm 8.08)$, the group that received soya bean oil also produced significantly $(\mathrm{p}<0.05)$ decreased ALP $(67.00 \pm 1.29)$ as compared to the ethanol group $(73.75 \pm 8.08)$. However, treatment with vitamin $\mathrm{C}$ and soya bean oil combined showed a significant $(\mathrm{p}<0.05)$ decreased in ALP $(61.50 \pm$ $2.72)$ as compared to the ethanol group $(73.75 \pm 8.08)$.

The present study shows that administration of ethanol for 28 days causes increased in the serum concentrations of AST, ALP and ALT which are biomarkers for liver damage. This also agree with the result of [25], which also shows that there was elevation in serum AST and ALT after 30days of ethanol administration in Wistar rats. The most prominent result of liver damage is the released of the intracellular enzymes AST, ALP and ALT from the liver into the blood. The serum concentrations of AST, ALP and ALT can serve as indicators of the state of the liver. Higher levels of AST, ALP and ALT are indicators of liver damage [26]. Therefore, the increased in the serum concentration of AST, ALP and ALT after ethanol administration reveals the liver damage caused by ethanol in Wistar rats. It is now generally accepted that oxidative stress plays an important role in the pathogenesis of ethanol toxicity [27, 28]. The close relation between ethanol and liver is due to the fact that more than $80 \%$ of ingested ethanol is metabolized in the liver without a feedback mechanism. In early phase, oxygen and NO-radicals derived from the complete oxidation of ethanol and acetaldehyde in excess markedly alters the intracellular redox status, induces fat deposits and triggers the inflammatory and immune response [29]. Chronic alcohol consumption is an established risk factor for the development of hepatocellular carcinoma in patients with liver cirrhosis [30].

The decreased in the serum concentration of ALP, AST and ALT in groups treated with vitamin C and soya bean oil shows the anti oxidant potentials of vitamin $\mathrm{C}$ and soya bean oil. The results obtained above revealed that vitamin $\mathrm{c}$ and soya bean oil have a strong antioxidant potential in ameliorating the oxidative damage caused by ethanol on the liver. Vitamin C (Ascorbic acid) is well known for its antioxidant activity, acting as a reducing agent to reverse oxidation in lipids [31]. Soya bean oil ranks first in worldwide production of vegetable oils. Soya bean decrease the risk of various diseases and pathological conditions, including various types of cancers, osteoporosis, menopause symptoms and coronary heart diseases. Flavonoids which are one of the components of soya bean have gained importance as scavengers of free radicals and a potent inhibitor of lipid peroxidation. It has been reported that population having high intake of isoflavones show lower incidence of cardiovascular diseases, osteoporosis, kidney disease and cancer risk [32]. 


\section{Conclusion}

In conclusion, the results obtained in this study revealed that alcohol administration to Wistar rats for four weeks induces oxidative stress. However Soya beans and vitamin $\mathrm{C}$ ameliorate the effects of the oxidative stress in the tested biomarkers.

\section{References}

[1] Rhoades, R.A. and Tanner, G.A. (2004). Medical Physiology. Lippincott Williams and Wilkins, $2^{\text {nd }}$ Ed

[2] Moore, K.L., Dalley, A.F. (2006). Clinically Oriented Anatomy. Lippincott Williams and Wilkins, $5^{\text {th }}$ Ed.

[3] A.B. Alhassan, Effects of Drugs on Health and Performance of Athletes" Jour. of Educ. Media and Technology, 1991; Vol. 3, No 1, 205-217

[4] J.A. Akpala, R.O. Bolaji, Adolescents and Psychosocial Problems. Lagos, Nigeria: Longman, 1991

[5] S. Das, V.K. Alagappan, D. Bagchi, H.S. Sharma, N. Maulik, D.K. Das, Coordinatedinduction of iNOS-VEGF-KDR-eNOS after resveratrol consumption: A potential mechanism for resveratrol preconditioning of the heart. Vascul. Pharmacol. 2005, 42, 281-289.

[6] A.H. Mokdad, J.S. Marks, D.F.Stroup, J.L.Gerberding, Actual causes of death in the United States. JAMA: 2000; 291: 1238-1245.

[7] Diagnostic and Statistical Manual of Mental Disorders, American Psychiatric Association: Washington, DC, USA. 1994; 4th ed

[8] B.F.Grant, F.S.Stinson, T.C. Harford, Age at onset of alcohol use and DSM-IV alcohol abuse and dependence: A 12-year follow-up. Journal of Substance Abuse; 2001.13: 493-504.

[9] A. George, V.M. Figueredo, Alcohol and arrhythmias: A comprehensive review. Journal of Cardiovacular Medicine. (Hagerstown) 2010; 11:221-228.

[10] V. Marinho, J. Laks, E. Engelhardt, D. Conn, Alcohol abuse in an elderly woman taking donepezil for Alzheimer disease. Journal of Clinical Psychopharmacology, 2006; 26: 683-685.

[11] T. Ohkubo, H. Metoki, Y. Imai, Alcohol intake, circadian blood pressure variation, and stroke. Hypertension, 2009;53: 4-5.

[12] A.I. Cederbaum, Y. Lu, D. Wu, Role of oxidative stress in alcohol-induced liver injury. Archives of Toxicology. 2009; 83: 519-548.

[13] H.K. Seitz, P. Becker, Alcohol metabolism and cancer risk. Alcohol Research Health. 2007; 30:38-47.

[14] M.J.Morris, Alcohol breath testing in patients with respiratory disease. Thorax, 1990; 45: 717-721.

[15] D.O. Baliunas, B.J.Taylor, H. Irving, M. Roerecke, J. Patra, S. Mohapatra, J. Rehm, Alcohol as a risk factor for type 2 diabetes: A systematic review2009.

[16] Y. Chen, L. Cui, J. Liao, L. huang, Effects of alcohol on bone metabolism and biomechanical property of mice. Sheng, Wu, Yi Xue Gong Cheng Xue Za Zhi, 2009; 26: 780-782.

[17] R.G. Smart, R.E. Mann, Alcohol and the epidemiology of liver cirrhosis. Alcohol Health \& Research World 16(3):217-222, 1992.

[18] I. Kurose, H. Higuchi, S. Kato, S. Miura, H. Ishii, Ethanol-induced oxidative stress in the liver. Alcoholism: Clinical and Experimental Research 20(1):77A-85A, 1996.

[19] E. Mezey, C.J. Kilman, A.M. Diehl, M.C. Mitchell, H.F. Herlong, Alcohol and dietary intake in the development of chronic pancreatitis and liver disease in alcoholism. American Journal of Clinical Nutrition 48:148-151, 1988.

[20] Heckman, J. R., Angle, J. S. and Chaney, R. L. (2005). "Residual Effects of Sewage Sludge on Soybean: II. Accumulation of Soil and Symbiotically Fixed Nitrogen" (PDF). Journal of Environmental Quality (Soil Science Society of America) 16 (2): 118-124.

[21] T.Y. Faremi, S.M. Suru, M.A. Fafunso, U.E. Obioha, Hepatoprotective potentials of Phyllanthus amarus against ethanol-induced oxidative stress in rats. Food Chem Toxic 2008; 46(8): 2658-2664.

[22] L.E. Ochuko, A.A. John, O.A. Rachael, O.Y. dejobi, S.O. Okafor, Adenekan, Protective effect of pineapple (Ananas cosmosus) peel extract onalcohol-induced oxidative stress in brain tissues of male albino rats. Asian Paicfic Journal of Tropical Disease, 2011;5-9

[23] Tietz NW, Prude EL and Sirgard- Anderson O (1994). Tietz Textbook of clinical chemistry.2 ${ }^{\text {nd }}$ edition,W.B. Saunders Company, London, pp.1354-1374.

[24] R.C.,Duncan., R.G., Knapp and M.C Miller,. (1977): Test of hypothesis in population Means. In: Introductory Biostatistics for the health sciences. John Wiley and Sons Inc. NY: 71-96.

[25] C. Daye, K. Hong, The Effect of LyciumBarbarumPolysaccharide on Alcohol-Induced Oxidative Stress in Rats. Molecules, 2011:16;2542-2550

[26] K.O. Lindros, Alcoholic liver disease: pathobiological aspects. J Hepatology 1995; 23: 7-15 Lindros KO. Alcoholic liver disease: pathobiological aspects. J Hepatology 1995; 23: 7-15

[27] J. Balkan, S. Dogru -Abbasoglu, O. Kanbagli, U. Çevikbap, G. Aykaç-Toker M. Uysal, Taurine has a protective effect against thioacetamide-induced liver cirrhosis by decreasing oxidative stress. Hum Exp Toxicol 2001; 20: 251-254

[28] C. Diez-Fernandez, N. Sanz, A.M. Alverez, A. Zaragoza, M. Cascales, Influence of aminoaguanide on parameters liver injury and regeneration induced in rats by a necrogenic dose of thioacctamide. Br J Pharmacal 1998; 125: 102-108

[29] T.R. Morgan, S. Mandayam, M.M. Jamal, Alcohol and hepatocellular carcinoma. Gastroenterology, 2004, 127, S87-96.

[30] G.P. McGregor, H.K. Biesalski, Rationale and impact of vitamin C in clinical nutrition. Current opinion in clinical nutrition and metabolic care9, 2006; (6): 697-703.

[31] S. Bor, C. Bor-Caymaz, N.A. Tobey, Esophageal exposure to ethanol increases risk of acid damage in rabbit esophagus. Dig Dis Sci; 1999;44:290-300.

[32] C.S. Lieber, Alcoholic fatty liver: Its pathogenesis and mechanism of progression to inflammation and fibrosis. Alcohol, 2004; 34:919.2004 